\title{
Leaping onwards and upwards amid challenges of the global pandemic: looking back on 2020, and ahead to 2021
}

\author{
Veronica Charlotte $^{1} \cdot$ Charlotte Cross $^{2}$
}

Accepted: 18 January 2021 / Published online: 2 February 2021

(c) The Malaysian Rubber Board 2021

The Journal of Rubber Research's (JRUR) very first Editorial in January 2020 highlighted publication of its inaugural online Volume 22 in 2019, and marked the major milestone of 90 years of publishing history. A year on, we are faced with unprecedented circumstances, as 2020 was a challenging year for the world. STEM in particular has encountered many difficulties, as scientists and researchers have had to contend with restricted travel, increased family responsibilities and closed borders.

In the face of this adversity, the scientific community has found new ways to collaborate virtually given the loss of traditional platforms, such as face to face discussions, meetings and conferences. Scientific communication is an integral part of global evolution, and like various other categories of society, researchers have had to adapt to online methods of communication and dissemination of knowledge. We are proud to say that JRUR continues to support, encourage and acknowledge efforts of the international academic community in these very difficult circumstances.

JRUR's four issues of Volume 23, published during this demanding year, have been well received. We have seen an increase in the number of articles published, as well as a growing readership. Now more than ever, authors who publish with JRUR can be sure that their work is reaching readers across the globe and contributing to scientific discourse. 2020 also saw an increase in both submissions and accepted articles. JRUR's annual performance is further realised by achievements in view of journal metrics, namely the impact factor (IF) ranking as reported by Clarivate Analytics.
We are very happy to be able to share that JRUR's IF has increased significantly to 0.353 (2019) and 5 year IF to 0.393 .

As we embark on the new Volume 24, in 2021, JRUR aims to publish 5 issues, including an additional Special Issue (SI) on the theme "New challenges and methods in the experimental investigation and modelling of elastomers". The Guest Editors assigned for this SI are Prof Dr Michael Johlitz of the Institute of Mechanics, Bundeswehr University Munich, Germany and Prof Dr Stefan Hartman from the Institute of Mechanics, Clausthal University of Technology, Germany. The objective of this issue is to bring international specialists from across Europe and Asia together, to exchange experiences, to discuss scientific results and to create new ideas and approaches.

Special thanks are due to the excellent authors who have made the growing success of JRUR possible, coupled with the timeless role of its esteemed Editorial Board, reviewers and Editorial Committee who work together to realise the goals of the journal. We truly appreciate the outstanding work of our team of subject matter experts, and we look forward to continuing this upward trend in 2021 and in the years ahead, as we approach JRUR's centennial.

Publisher's Note Springer Nature remains neutral with regard to jurisdictional claims in published maps and institutional affiliations.

Veronica Charlotte

veronica@lgm.gov.my

1 Publications and Library Unit, Malaysian Rubber Board, 50450, 148, Jalan Ampang, Kuala Lumpur 50450,

Wilayah Persekutuan, Malaysia

2 Springer Nature, London, United Kingdom 